Supporting information for

\title{
Entrapment of Enzymes within Sol-Gel-Derived Magnetite
}

Andrey S. Drozdov ${ }^{\mathrm{a}}$, Olga E. Shapovalova ${ }^{\mathrm{a}}$, Vladimir Ivanovski ${ }^{\mathrm{b}}$, David Avnir ${ }^{\mathrm{c}}$ and Vladimir V. Vinogradov ${ }^{\mathrm{a}}$

${ }^{a}$ Laboratory of Solution Chemistry of Advanced Materials and Technologies, ITMO University, St.Petersburg, 197101, Russian Federation E-mail: drozdov@scamt.ru; vinogradoffs@mail.ru.

${ }^{b}$ Ss. Cyril and Methodius University in Skopje, Faculty of Natural Sciences and Mathematics, Institute of Chemistry, Skopje, 1000, Republic of Macedonia. Email: vladimir.ivanovski@yahoo.com

${ }^{c}$ Institute of Chemistry and the Centre for Nanoscience and Nanotechnology, the Hebrew University of Jerusalem, Jerusalem, 91904, Israel.E-mail: david.avnir@mail.huji.ac.il 
SEM image of the magnetite nanoparticles

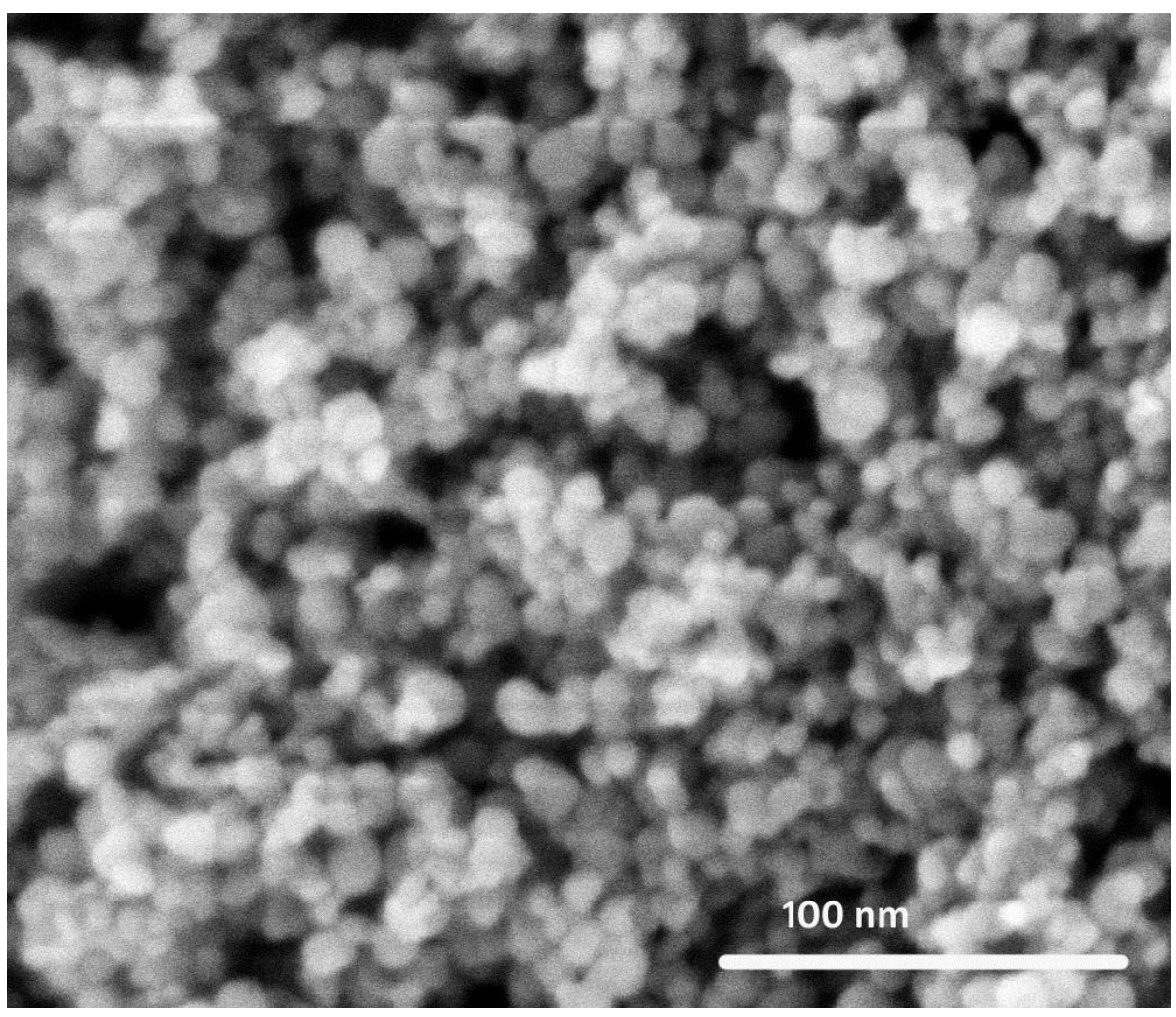

Figure 1S. HR-SEM image of the particles of the pure ferria hydrosol. 


\section{ATR spectra of free, adsorbed and entrapped OVA}

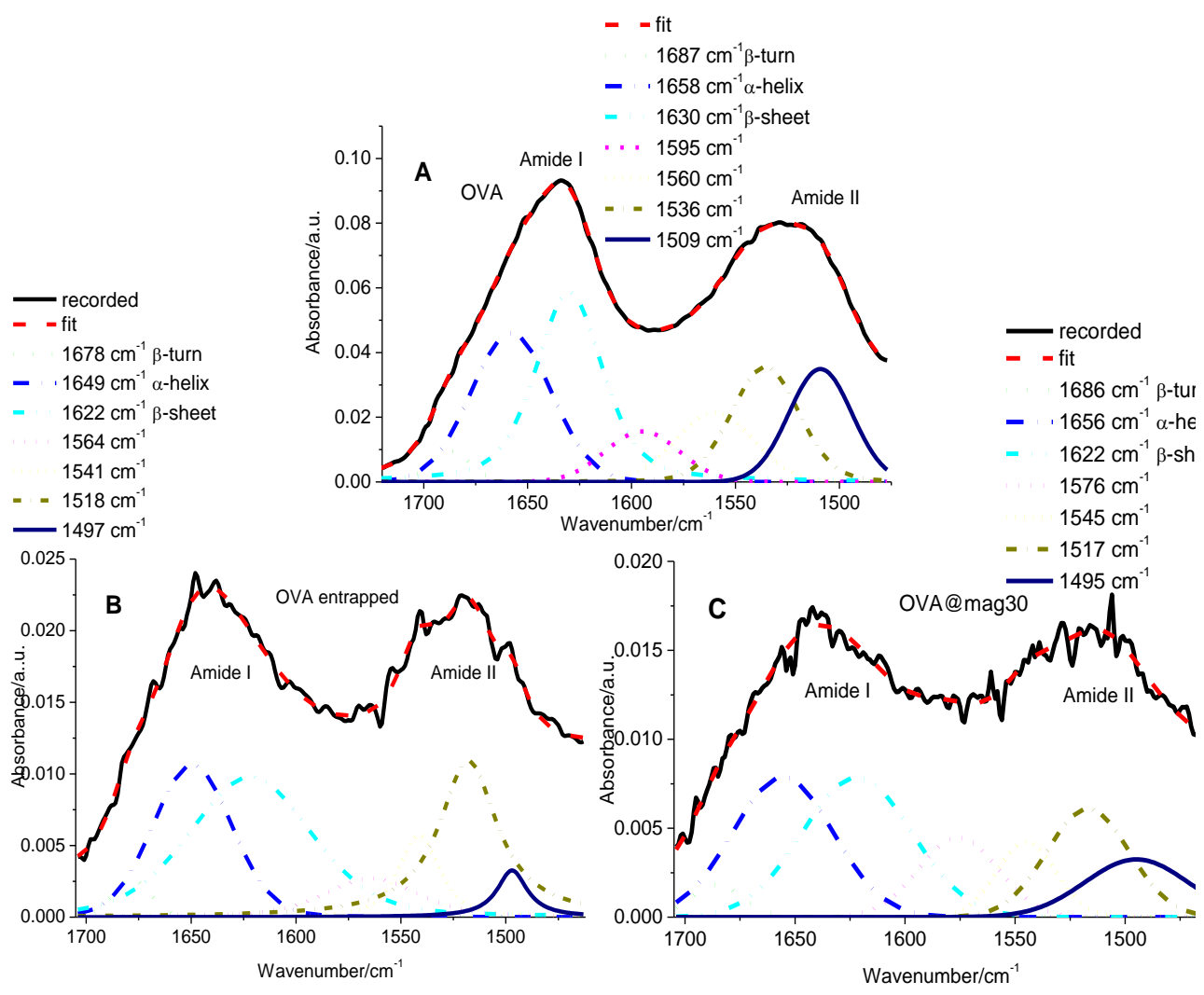

Figure 2S. Fitted ATR spectra of OVA in the region of the amide I and amide II bands for (A) pure OVA, (B) OVA@magnetite, and (C) adsorbed OVA on magnetite nanoparticles. 


\section{$\underline{\text { Texture characteristics of magnetite matrix and composite material }}$}
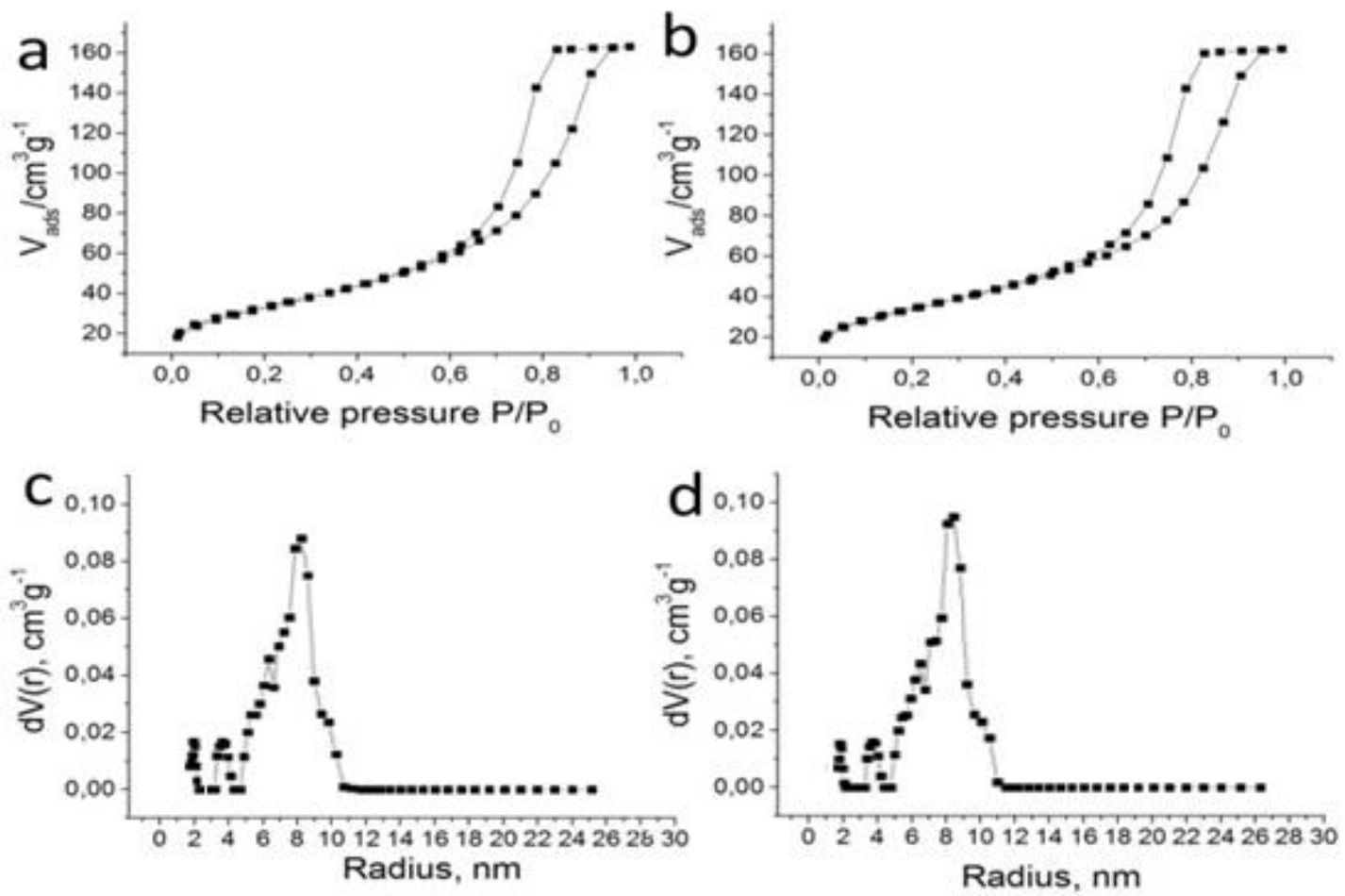

Figure 3S. $\mathrm{N}_{2}$ adsorption-desorption isotherms on (a) a pure ferria matrix, and (b) on $\mathrm{CAB} @$ ferria. Pore size distribution (c) of a pure ferria matrix, and (d) of CAB@ ferria. See Table $1 \mathrm{~S}$ for the measured values.

Table 1S. Porosities and surface areas of ferria and CAB@ferria

\begin{tabular}{ccccc}
\hline Sample & $\begin{array}{c}\text { Surface area, } \\
\mathrm{m}^{2} / \mathrm{g}\end{array}$ & $\begin{array}{c}\text { Total pore } \\
\text { volume }, \mathrm{cm}^{3} / \mathrm{g}\end{array}$ & $\begin{array}{c}\text { Average pore } \\
\text { diameter, } \mathrm{nm}\end{array}$ & Porosity \\
\hline ferria & 120 & 0.287 & 8.5 & 0.52 \\
CAB @ ferria & 120 & 0.263 & 8.2 & 0.52 \\
\hline
\end{tabular}




\section{Experimental data of the enzymatic activity measurement}
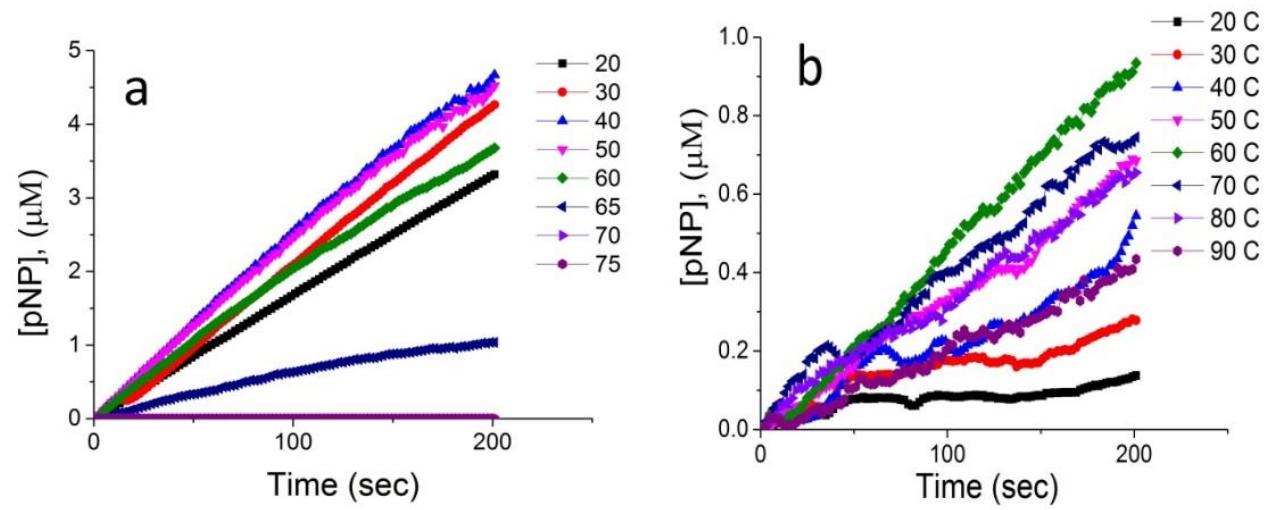

Figure 4S. Enzymatic activity measurements of (a) free CAB, and (b) CAB@ferria composite at different temperatures. The free enzyme completely loses its activity at $70{ }^{\circ} \mathrm{C}$ while the composite still performs reaction even at $90{ }^{\circ} \mathrm{C}$. 


\section{Equations for calculations of true activation energy and Arrhenius pre-factor}

We use the model described in ref. 1S, tailored for systems with large Thiele modulus, that is, systems where the internal diffusion limits the overall rate of reaction), for which:

$$
\left(\frac{3}{r} \sqrt{D_{e}}\right) A^{1 / 2}\left[\exp \left(\frac{-E_{a}}{R T}\right)\right]^{1 / 2}=A^{\prime}\left[\exp \left(\frac{-E_{a}^{\prime}}{R T}\right)\right]
$$

Where $r$ is a mean catalyst grain radius, $D_{e}$ is an effective diffusion coefficient, $A$ is a true Arrhenius pre-factor where, $A^{\prime}$ is apparent Arrhenius pre-factor calculated from experiment data, $E_{a}$ is a true activation energy, $E_{a}^{\prime}$ is apparent activation energy calculated from experiment data, $R$ is the gas constant, $T$ is a temperature. Taking into account, that for systems with large Thiele modulus $E_{a}$ is approximately equal to $2 E^{\prime}{ }_{a}$ (see ref. $1 \mathrm{~S}$ for details) it is possible to rewrite equation (1) in following form

$A=\frac{\left[A^{\prime} * \exp \left(\frac{-E_{a}^{\prime}}{R T}\right)\right]^{2}}{\frac{9}{r^{2}} D_{e} \exp \left(\frac{-2 E_{a}^{\prime}}{R T}\right)}$

$D_{e}$ was calculated empoying equation (3)

$D_{e}=\frac{D_{s} \sigma \phi_{p}}{\check{\tau}}$

where $D_{s}$ is the diffusion coefficient in solution (valued at $7 * 10^{-6} \mathrm{~cm}^{2} / \mathrm{s}$ ), ${ }^{2 \mathrm{~S}} \sigma$ is the constriction factor taken as $0.15,{ }^{3 \mathrm{~S}} \phi_{p}$ is the porosity taken as 0.52 from Table $1 \mathrm{~S}$ ), $\check{\tau}$ is the tortuosity, taken as $3 .^{4 \mathrm{~S}}$ Then from equation (3), $D_{e}$ is $=1.8 * 10^{-7} \mathrm{~cm}^{2} / \mathrm{s}$. Finally, substituting into equation 2 this values as well as $E_{a}^{\prime}=38 \mathrm{~kJ} / \mathrm{mol}, A^{\prime}=45.6 \mathrm{~s}^{-1}, T=298 \mathrm{~K}, r$ $\sim 10^{-4} \mathrm{~cm}$ (from DLS measurements, see fig. 5S), one gets $A=13 \mathrm{~s}^{-1}$ 


\section{DLS measurements of the hydrodynamic diameter of the composite particles}

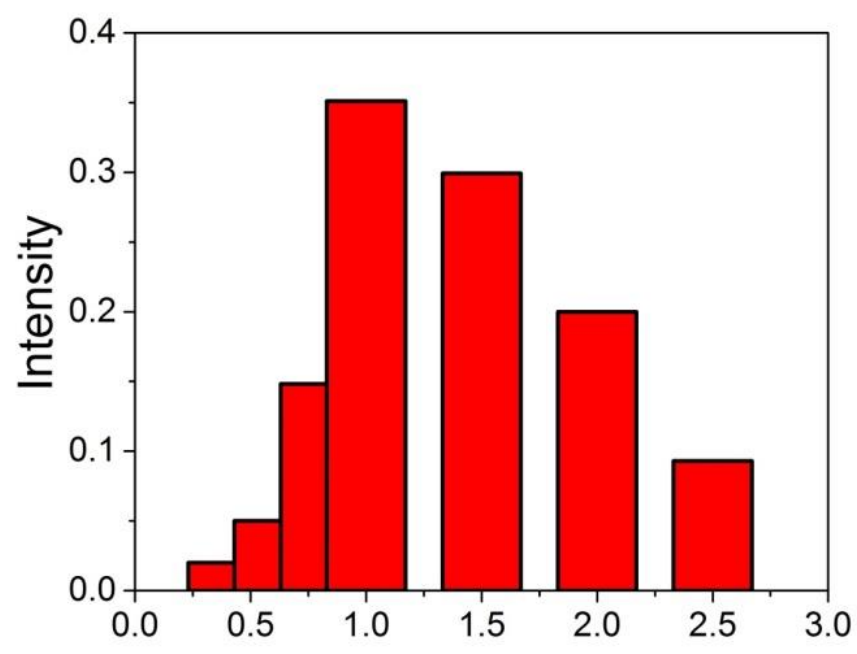

Hydrodynamic diameter, $\mu \mathrm{m}$

Figure 5S. Particles diameter distribution of the composite particles used in the enzymatic activity experiments. 


\section{Electrostatic potential of the surface of a CAB molecule}

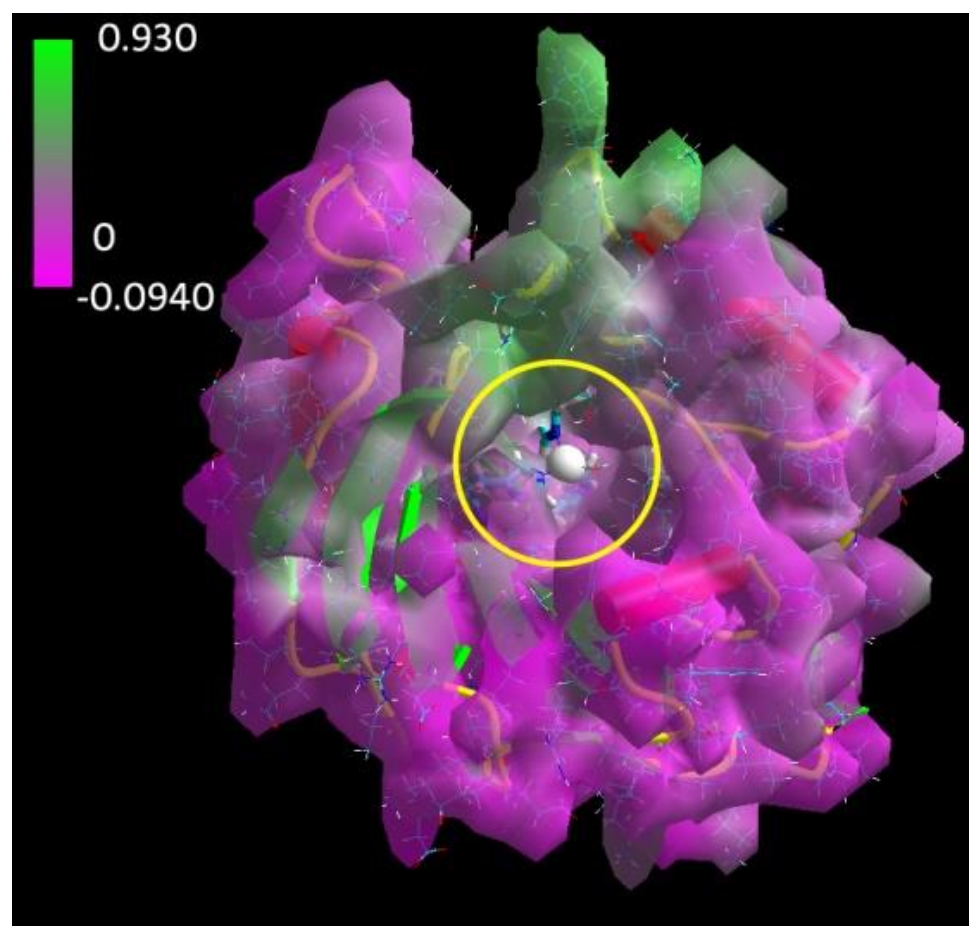

Figure 6S. The electrostatic surface potential of a $\mathrm{CAB}$ molecule. Positively charged zones are marked green, and negatively charged zones are marked purple. The cavity with the active site (yellow circle) is composed of His95, His96, His116 and $\mathrm{Zn}^{2+}$. (The visualization was done with HyperChem 8.08. The protein structure is described in ref. $5 \mathrm{~S}$. The structure file was obtained from www.pdb.org). 


\section{The zeta potential as a function of $\mathrm{pH}$ of the ferria hydrosol}

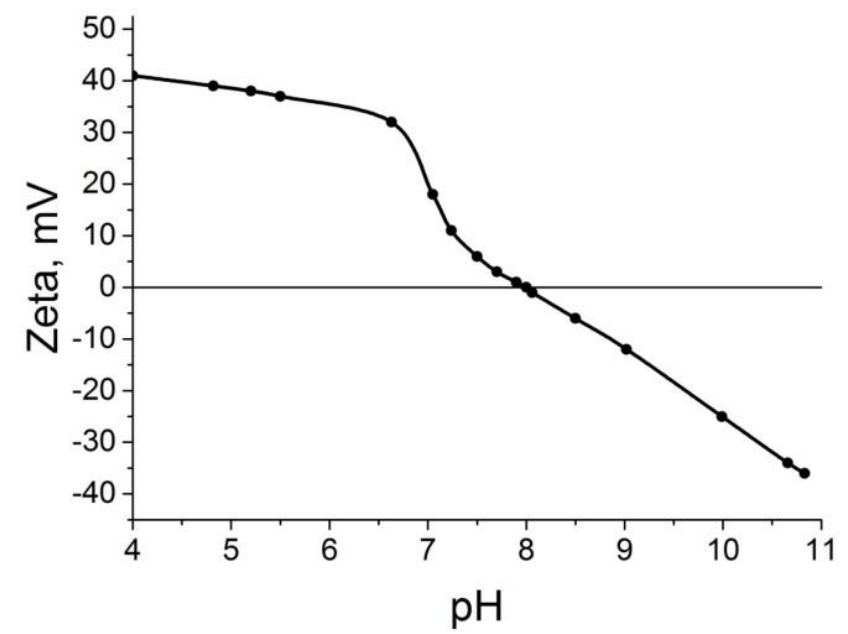

Figure 7S. Zeta potential of the magnetite sol as a function of the $\mathrm{pH}$. The isoelectric point of the hydrosol is at $\mathrm{pH} 8$

\section{References}

1S. Fogler, H. S. Elements of Chemical Reaction Engineering $4^{\text {th }}$ edition, 2015, 846.

2S. Bird, R. B., Stewart, W. E., Lightfoot, E. N. Transport phenomena, 2002, 528.

3S. Protasova, L. N., Rebrov, E. V., Glazneva, T. S., Berenguer-Murcia, A., Ismagilov, Z. R., Schouten, J. C. Control of the thickness of mesoporous titania films for application in multiphase catalytic microreactors. J. Catal., 271, 2010, 161-169.

4S. Salmas, C. E., Androutsopoulos, G. P. A novel pore structure tortuosity concept based on nitrogen sorption hysteresis data. Ind. Eng. Chem. Res., 40, 2001, 721-730.

5S. Saito, R., Sato, T., Ikai, A., Tanaka, N.. Structure of bovine carbonic anhydrase II at 1.95 Å resolution. Acta Crystallogr., Sect. D: Biol. Crystallogr. 60, 2004, 792-795. 